\title{
Development of a Project Level Performance Measurement Model for Improving Collaborative Design Team Work
}

\author{
Yuanyuan Yin, Shengfeng Qin, Ray Holland \\ School of Engineering and Design, Brunel University, Middlesex, Uxbridge UB8 3PH UK \\ Yuanyuan.yin@brunel.ac.uk,.Sheng.feng.qin@brunel.ac.uk,Ray.holland@brunel.ac.uk
}

\begin{abstract}
This research explored a new direction of improving collaborative design by performance measurement. More specifically, a novel 3-dimensional performance measurement model is developed and the purpose of this model is to help project managers improve team collaboration by indicating strengths and weaknesses of team members during the project development process. Considering the complexity of collaborative design work, a multiple criteria model is proposed to reflect the design dynamics, which highlights five performance indicators: efficiency, effectiveness, collaboration, management skills and innovation. These five indicators are mostly influenced by role-based performance measurement criteria (the second dimension). Design and development process (time) is also considered (the third dimension). This $3 D$ model allows all involved design participants to measure work performance at any time during the product development process. In order to develop this model, the role-based task analysis and industrial survey methods were utilized. Three groups of role-based product design and development performance measurement criteria were identified for measuring design performance of the top managers, middle managers and individual designers in a project team. A 3-dimensional performance measurement method was proposed to calculate final performance scores from a performance measurement matrix. The proposed model was evaluated as a tool which can support project managers to reduce potential design and collaboration risks and increase confidence in decision-making process. The model has been discussed on implementing in a web-based application for measuring design performance throughout the product design and development process.
\end{abstract}

Keywords: Collaborative design, performance management, role-based task analysis, 3D performance measurement modeling, design management

\section{Introduction}

During the past two decades, collaborative design has experienced some major technological innovations and paradigm shifts [1]. Generally, the collaborative design is an activity that requires participation of individuals for sharing information and organizing design tasks and recourses. Particularly in a complex and large project, design often involves multiple persons or groups collaborating in a design process, sharing design information, negotiating and decision-making, coordinating and managing design tasks and activities [2]. Therefore, the effectiveness of collaborative design process becomes critical for design project management. And how to improve the effectiveness of a collaborative design is a challenging issue in the field of collaborative design.

Current collaborative design research addresses this issue from different aspects, such as the development of various CAD-based collaborative design tools [1,7] to provide an interoperable design modeling and communication platform, design information and knowledge sharing systems to reduce design conflicts [3, 4, 5] and web-based design negotiation and coordination tools for bettering collaboration $[3,6]$.

Although recent research [8] has shown that a regular self-performance assessment of a collaborative design can improve the design effectiveness significantly, only a few researchers focused on management of activities, especially from a performance measurement aspect to improve project team collaboration.

This research explored a new direction of collaborative design which can support collaborative design by implementing project team performance measurement. The structure of the paper is shown as follows. Firstly, related works are presented in Section 2 and then Section 3 describe proposed research methods to identify key performance indicators for a collaborative design project and further develop a 3D performance model. The discussion on implementing this model into a web-based 3D performance measurement tool is followed in Section 4. Finally, Section 5 presents the conclusions of this research.

\section{Related works}

Many existing collaborative design research were focused on: information sharing system: enterprise resource planning $[3,4,5]$; web-based system based on HTML, XML, VRML, Java etc $[3,6]$; computer-aided systems: computer-aided design, computer-aided engineering, computer-aided manufacturing [1, 7]. These studies concentrated on the technical side of 
design supporting tools. Merlo [9] presented a design information and knowledge sharing systems to reduce design conflicts. Li et al. [1] developed a CAD-based 3D streaming technology, which can effectively transmit visualization information across networks for Web applications. Other researchers [7] created a web-based conceptual design prototype modeling system to support collaborative design. These researches focused on the technical side of design supporting tools.

There are also some studies $[10,11,12,13]$ addressing the management side of a collaborative design project and teamwork $[11,12,13]$. Collaboration is regarded as an activity where a large task is achieved by a team. Often the task is only achievable when the collective resources are assembled [10]. Contributions to the work are negotiated and mediated through communications and sharing of knowledge. Successful collaboration requires effectiveness in a number of areas: cognitive synchronization/reconciliation; developing shared meaning; developing shared memories; negotiation; communication of data, knowledge information; planning of activities, tasks, methodologies; and management of tasks [11].

From the management side of collaborative design studies, Busseri et al [8] tested the hypothesis that regular assessment of the way teams function can help improve team performance by a case study of a team of building designers on an artificial design project. They concluded that instructing a group to measure its performance through a design process led to: significantly higher levels of self-rated and observerrated group effectiveness; significantly higher levels of self-rated group satisfaction; double the number of positive comments (compared to negative comments) from team members. This means that performance measurement action does help team collaboration.

In the performance research area, Performance Measurement (PM) has been much discussed in both academic and practitioner literature [14-18]. Research has discussed PM from different viewpoints, to indicate how to implement PM systems. A meta-analysis of determinants of new product development success identified 47 published research works that used a single measure of success or failure for product development [14]. Brown [15] emphasized the need for understanding the relationships between various matrices used for measuring product development performance. Salter [16] indicated that PM is based on the financial performance of a project rather than on other important objectives. Some papers explored the linkages between key features of the New Product Development (NPD) process and NPD performance and suggested ways of designing the process to improve performance [17]. These PM systems either using on a single measure of success or failure for product development or a single financial performance of a project are in general not focused on collaborative design process.
Given a great complexity of collaborative design work, PM will significantly become more accurate if multiple measures of performance are used. Therefore, this research studied existing PM criteria which might improve team collaborative deign in product development process, and developed five multiple measurement items which can be used to measure in conformity during the product design process, which are efficiency, effectiveness, collaboration, management skill, and innovation. Based on these five PM indicators, a performance measurement model has been developed to improve collaborative design.

\section{Research Methods and Results}

In order to identify fundamental principles of collaborative design and PM criteria, and how to implement PM criteria to improve product collaborative design, a literature review, industrial surveys and rolebased task analysis were employed. The objectives of the literature review were to study the existing collaborative design principles and design PM criteria from academic research, and investigate how PM have been implemented in the last decade. The objectives of the industrial survey was to find out a) how companies implement collaborative design, b) investigate current problems, c) create design PM matrices, d) evaluate research outcome. Seven relevant managers recommended by the top managers in seven different companies were interviewed. Among these seven managers, three are in China and four are in the UK. Furthermore, a deep observation research in two companies in the UK was conducted. Role-based task analysis was carried out to differentiate team members' responsibilities and duties of collaborative design. And Collaborative design PM criteria were created according to different design activities of different team members.

\subsection{Role-based task analysis}

Harsh competition has led to increased emphasis on creativity and innovation as a crucial dimension in business. In response, it is suggested that designers are undertaking a leadership role in the product development process [19]. Scholars suggest design responsibilities should expand to roles that support the whole project collaboration effort. Consequently, project collaboration involves every team member's contribution. Based on the above, collaborative design can be defined as a creative process that includes all the activities throughout the project development. And it is relevant with each project team member's contribution. Thus, the team collaborative design performance can be viewed as an aggregate of team member's collaborative design performance.

Organizational process factors in NPD are associated with achievement of operational outcome targets for product quality, unit cost, and time-to-market [20]. From an organizational point of view, this research 
considered that a project team should have three levels: top management, middle management and individual staff (Figure 1). Every product design project should have an investment manager or a CEO as the top manager to control and take an overall responsibility. Then, there should be several middle layer managers to administer different sectors in the product design and development. Depending on the size and complexity of the project, the number in the middle management layer can vary from zero to several people. Finally, under each middle layer manager there are some individual workers at the bottom. The individual layer is composed of engineers, designers, marketing people, and sales staff, etc. Within this structure, all the involved design participants are included in the performance measurement and management system in order to improve the whole team collaboration performance. In the structure, each role can be a person, a group, or an organization, and they might come from different organizations.

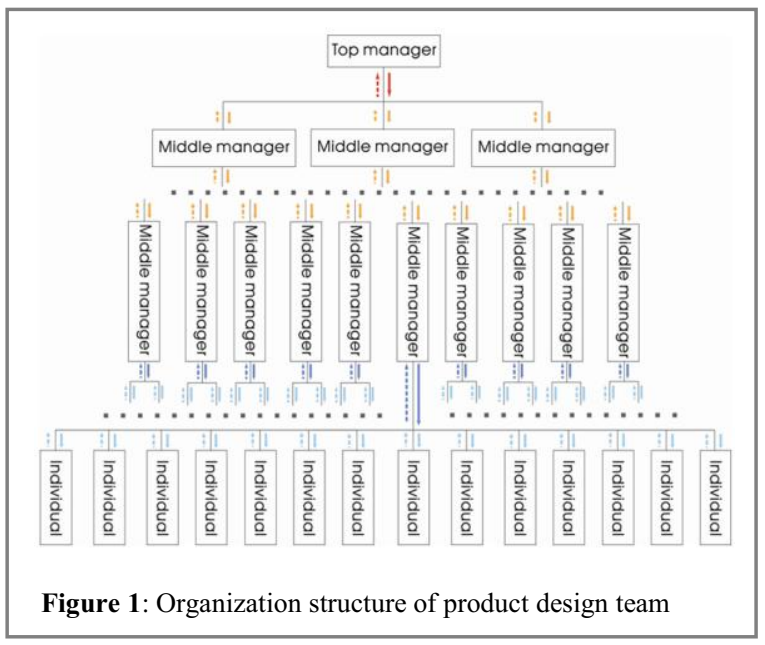

\subsection{4-D performance measurement method}

The 360 degree appraisals appear to be taking toot and becoming an established form of appraisal in the UK. A survey by consultants Pilat reported up to 40 percent of FTSE companies are now using this approach. Some organizations also use online computerized datagathering systems as well as more informal systems where manager simply pass a disk around a number of appraisers [21].

Based on 360-degree appraisal principles, the author developed a 4 dimensional performance measurement method to collect data and measure project team members' design performance. Project members' performance can be evaluated from four dimensions: comments from the high level manager, feedback from the lower level staff, comparison with the same level staff and self-performance. (See figure 2) And all the PM feedback will be analyzed according to the PM criteria from the five design items.
This method will help project managers well understand strengths and weaknesses of each team member during project development process, and then the managers can reduce the risks of potential collaboration mistakes and get confidence in decisionmaking.

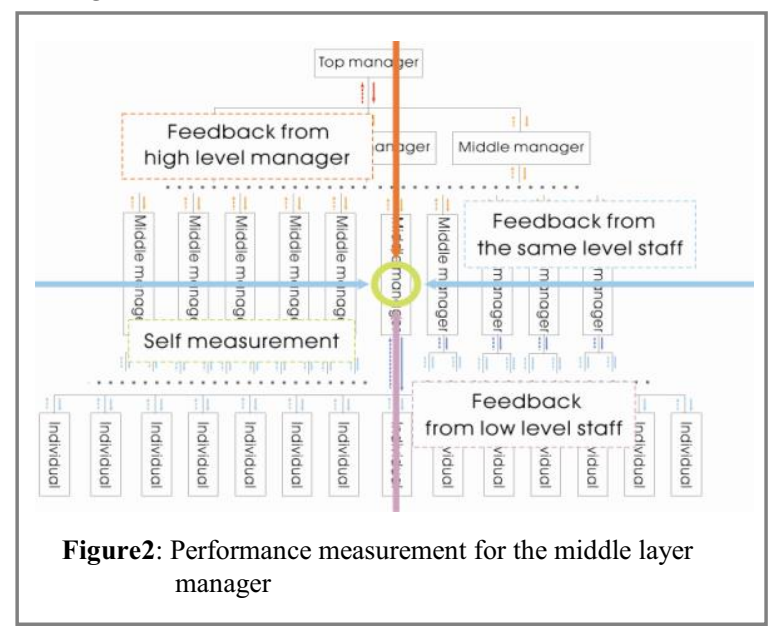

\subsection{Industrial Survey and PM Matrix}

According to the above role-based model of a product design team (see figure1), industrial interviews and questionnaire surveys were conducted in the UK with 30 design staff from 6 industrial companies was conducted to distinguish and clarify different design PM matrices for different levels of members, and detail PM criteria for each design PM item and the system structure. They are all with rich experiences in collaborative design as industrial designers, design managers, product engineers and project managers etc. As for the questionnaire study, there were 126 responses to the questionnaire survey.

$86 \%$ of the interviewees believed the proposed model was a reasonable and operable design performance measurement and management system which could be implemented in various industrial organizations. They also suggested that the model should be further developed to include more details about how to link the five performance measurement items with practice behaviors.

Based on the literature review [14-18] in collaborative design and PM, 42 general design PM criteria were generated based on the five design PM criteria items. Meanwhile, as leaders or managers, they should have some specific management characteristics. For instance, Belbin [22] highlighted plant, resource investigator, coordinator, monitor evaluator and so on to describe manager-roles contributions. Shead [23] founded eight key factors and four different leadership roles which could be used together to measure leader's or manager's performance to improve team work effectiveness. Concluded from secondary research, a summary that includes 24 criteria for manager's leadership performance measurement is created. 
As 42 general design PM criteria and 24 leadership PM criteria are too complex to be operated in a design performance measurement system, the second round industrial survey was conducted to identify the most important 5 design PM sub-criteria for each of the five criteria item.

Firstly, the survey asked interviewees to divide all design PM criteria into five groups followed the five design PM criteria items: efficiency, effectiveness, collaboration, management skill, and innovation. Secondly, interviewees need pick up the top five criteria from each of the five design performance criteria groups. In the end, interviewees were asked to give priorities for the top five criteria which they selected in the second stage. The results of the questionnaire survey indicate the following: (1) from an efficiency point of view, more than half the people regard problem solving skills as the most important factor to measure staff work performance. The efficiency factors are: work planning skill, decision-making efficiency, ability to finish work on time, and ability to work under pressure; (2) from an effectiveness aspect, more than half the people think the ability of delivering to the brief is important during the product design and development process. Similarly, for (3) management skill and (4) collaboration indicators, simplify complex information and the information sharing are important. In (5) innovation performance enhance customer experience is the most important factor.

Table 1: Design Performance Measurement Matrix

\begin{tabular}{|c|c|c|c|c|c|}
\hline 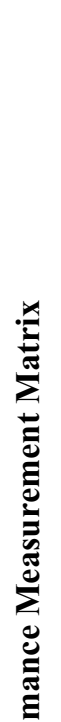 & 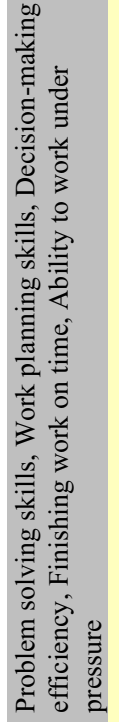 & 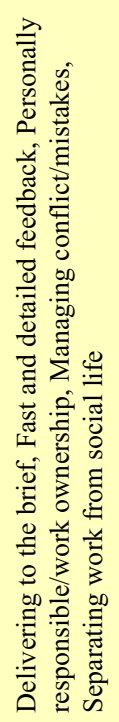 & 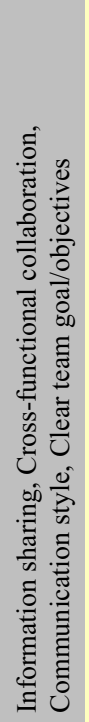 & 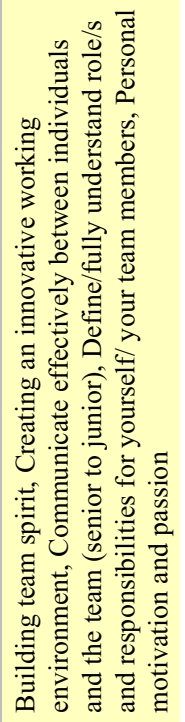 & 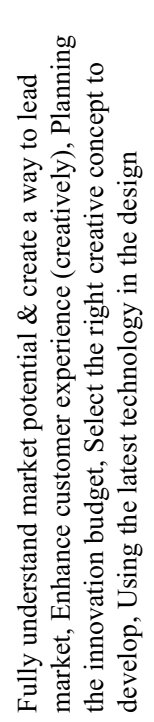 \\
\hline 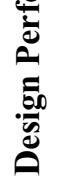 & 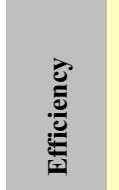 & 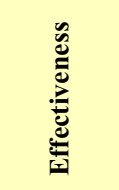 & 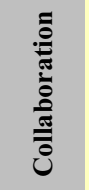 & 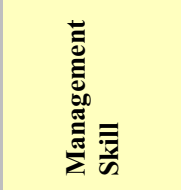 & 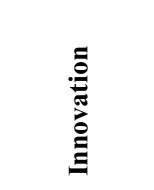 \\
\hline
\end{tabular}

According to results from the second round industry survey, a design performance measurement matrix was created and it could work as standards to evaluate staff's design performance during project development process (Table 1).

\subsection{D performance model}

A great deal of research about NPD process has been carried out focused on different perspectives [24-34]. Keinonen [24] and his colleagues reviewed the conceptual design development process of products in industry. They indicated product design is customarily linked to manufacturing; products fulfill the needs of customers, and business is built on the exchange of products. They identified three generic design activities for conceptual design: background research, concept generation and concept evaluation. A generic product design and development process was explored as marketing, R\&D, concept screening, detail design, user test, finalization design, and manufacturing [24-34].

Table 2: Product design and development process

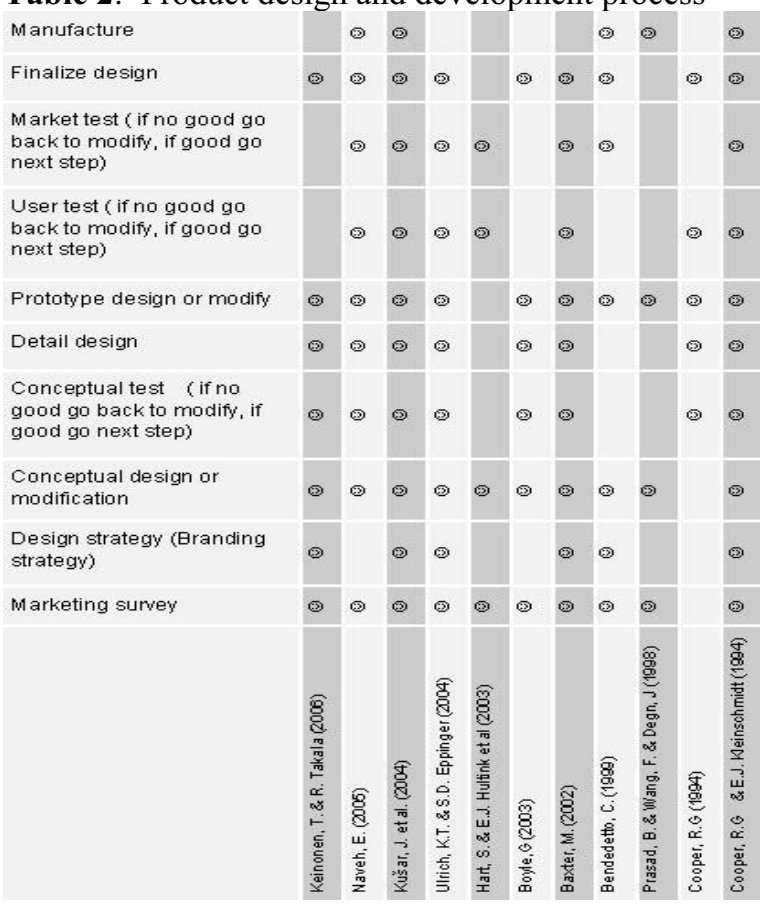

The authors compared different product design and development frameworks and synthesized the relevant research in order to build up an integrated product design and development process (Table 2). This comprehensive product design and development process can provide a clear understanding of all design activities which may be conducted in each section during the product design and development process.

Some researchers have related the NPD process with PM research, as different sections in the NPD process have different characteristics and different combinations of technical and commercial evaluation. Therefore, in order to get reasonable and precise design PM results, a 3-dimensional design PM model was created based on staff design activity score, the five design PM criteria 
items, and the product design and development process (Figure 3).

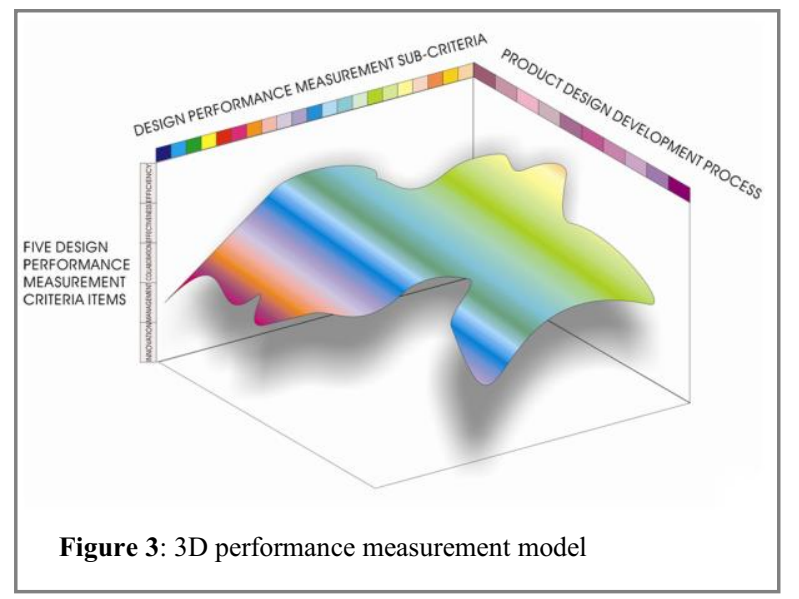

3.4.1 Model Evaluation. In order to test and evaluate whether the proposed PM matrix and the 3D PM model are suitable for different design projects, the authors conducted 3 month deep industrial field studies in two different types of design organizations (one and a half months for each): one is Design Bridge in London which is one of the best strategy and packing design consultancies in the UK; the other is Industrial Design Human Factor (IDHF) department in Xerox Corporation (Welwyn Garden City, UK) which is the world's leading document management technology and services enterprise. Most projects of Design Bridge are short term projects, and have close relationship with their clients, whilst the most projects from Xerox are long term projects, which involved more professionals with different backgrounds and more complicated development process. During the 3 month industrial field study, methodologies of observation research, interviews, questionnaires, focus group were utilized in these two companies to find out if the proposed model can support and improve project team collaborative design performance. The principal author participated in two design projects at Design Bridge, and one project at Xerox IDHF department. Based on their design practices and the observation of their design activities, process and management, we believe that our model is suitable for their design projects. It is evidenced by face-to-face formal interviews involving 19 people including top mangers, middle level managers, and individual staff with different backgrounds; and a questionnaire survey were conducted to test the suitability and feasibility of proposed 3D PM model at Design Bridge (three offices based on London, Singapore, and Holland), and Xerox IDHF. From the study, most of interviewees believe that the proposed PM matrix and the 3D PM model is helpful to support project mangers to improve team collaborative design, increase confidence in decision-making process, and deduce collaboration risks.

\subsection{Performance measurement methods}

The matrix has five design PM items in terms of efficiency, effectiveness, management skill, collaboration, and innovation. Each design PM item comprises several sub-criteria. During product design and development, the five design PM items have different weightings at different stages, and for each item, the sub-criteria may also have different weightings.

For a project team member, generally, assumes there are $\mathrm{N}$ colleagues under one manager and $\mathrm{P}$ staff under his/her leadership. There are m PM criteria in 5 items for self evaluation.

1) Figure out self-evaluation. Here $W_{i}$ is weightings for each sub-criteria, and $W F_{j}$ means weightings for each item at a specific stage.

$$
S_{S=} \sum_{j=1}^{5}\left(\sum_{i=1}^{M} f_{i j} W_{i}\right)^{*} W F_{j}
$$

2) PM scores from his/her colleagues

$$
S_{C=} \sum_{j=1}^{5}\left[\left(\sum_{i=1}^{N} C_{i j} / N_{]^{*}} W F_{j}\right.\right.
$$

3) PM scores from his/her individual staff

$$
S_{I=} \sum_{j=1}^{5}\left[\left(\sum_{i=1}^{P} I_{i j} / P_{]^{*}} W F_{j}\right.\right.
$$

4) $\mathrm{PM}$ scores from the manager

$$
S_{M} \sum_{j=1}^{5} M_{j} W F_{j}
$$

5) Synthesized score. As three groups of design performance measurement feedback may have different influence to the project final outcome,

here $W_{S}, W_{C}, W_{M}, W_{I}$ indicate different weightings for design performance measurement replies from staff self, colleagues and manager, and lower staff.

$$
\begin{aligned}
& S_{r}=S_{S} * W_{S}+S_{C} * W_{C}+S_{M} * \\
& W_{M}+S_{I *} W_{I}
\end{aligned}
$$

6) In order to minimize differences of team member and managers' marking style, normalized score is utilized to integrated analyze and compare different teams' design performance during the project development process.

$$
S_{N=} \frac{S}{\operatorname{Max}\left(S_{K}\right)_{K=1 \ldots N}} * 100 \%
$$




\section{Discussion and Conclusion}

This research explored a new research direction for collaborative design which aims to improve project collaborative design by regularly implementing team working member performance measurement. The proposed conceptual model for the performance measurement system has been developed and evaluated as a useful and operable design management tool for users, such as business managers, product managers, and designers to improve their project collaborative design, reduce potential collaboration risks, and increase confidence in decision-making process. The methodologies were effective in building and testing the model.

Future research will focus on a further development of a web-based design performance measurement tool which allows all the involved design participates to measure performance at anytime and anywhere. It has been designed that users can access the system with their user IDs. They can control and manage their own work at any time or measure lower level staff work performance if they are at manager levels. This tool needs to be evaluated effectively.

\section{References}

[1] W.D.Li, W.F. Lu, et al, Collaborative computer-aided design-research and development status, Computer-Aided Design 37, 2005, 931-940

[2] M. Chiu, An organizational view of design communication in design collaboration, Design Studies 23, 2002, 187-210

[3] S. Zhang, W. Shen, H. Ghenniwa, A review of internetbased product information sharing and visualization, Computers in Industry 54, 2004, 1-15.

[4] U. Roy, B. Bharadwaj, S.S. Kodkani, M. Cargian, Produce development in a collaborative design environment, Concurrent Engineering: Research and Applications 5 (4), 1997

[5] J. Numata, Knowledge Amplification: An Information System for Engineering Management, Sony's Innovation in Management Series, vol. 17, Sony Corporation, Japan, 1996

[6] W. Shen, J.P. Barthes, An experimental environment for exchanging engineering design knowledge by cognitive agents, in M. Mantyla, S. Finger, T. Tomiyama (Eds.), Knowledge Intensive CAD-2, Chapman \& Hall, London, 1996

[7] S.F. Qin, R.Harrison, A.A. West, I.N. Jordanov, D.K. Wright, A framework of web-based conceptual design, Computers in Industry 50, 2003, 153-164.

[8] M.A. Busseri, J.M. Palmer, Improving teamwork: the effect of self-assessment on construction design teams, Design Studies 21(n3), 2000, 223-238

[9] C. Merlo, Ph Girard, Information system modelling for engineering design co-ordination, Computers in Industry $55,2004,317-334$

[10] P. Girard, V. Robin, Analysis of collaboration for project design management, Computers in Industry 57, 2006, 817-826

[11] S.Y.T. Lang, J. Dickinson, T.O. Buchal, Cognitive factors in distributed design, Computers in Industry 48, 2002, 89-98

[12] A.C. Cross, N. Cross, Observations of teamwork and social processes in design, Design Studies 16 (2), 1995

[13] D.H. Sonnenwald, Communication roles that support collaboration during the design process, Design studies 17, 1996, 277-301
[14] M.M. Montoya-Weiss, R. Calantone, Determinants of new product performance: a review and meta-analysis, Journal of Product Innovation Management Vol.11, 1994, 397-417

[15] S.L. Brown, et al., Product development: past research, present findings, and future directions, Academy of Management Review Vol.20 (2), 1995, 343-378

[16] A. Salter, R. Torbett, Innovation and performance in engineering design, Journal of Construction Management and Economics Vol.21, 2003, 573-580

[17] E.U. Bond, B.A.mWalker et al., Reputational effectiveness in cross-functional working relationships, Journal of Product Innovation Management Vol.21, 2004, 44-601

[18] Y. Yin, S.F. Qin, R. Holland, Conceptual model of a web-based design performance measurement and management system, Processing of performance measurement management: public and private conference, 2006, 833-840

[19] B. Stamm, Managing Innovation, Design and Creativity. Chichester, UK: Wily \& Song, 2003

[20] M.V. Tatikonda, M.M. Montoya-Weisis, Integrating operations and marketing perspectives of product innovation: the influence of organizational process factors and capabilities on development performance, Journal of Management Science Vol.47 (1), 2001, 151172

[21] T. Redman, A. Wilkinson, Contemporary human resource management, London: Prentice Hall/FT, 2006

[22] R.M. Belbin, Team roles at work. England: ButterworthHeinemann, 1993

[23] A.G. Shead, A.P.Kakabadse, Mapping the transitional experience of switching leadership roles, Leadership \& Organization Development Journal, Vol.27 (7), 2006, 596-618

[24] T. Keinonen, R. Takala, Product concept design: a review of the conceptual design of product in industry. Germany: Springer, 2006

[25] E. Naveh, The effect of integrated product development on efficiency and innovation, International Journal of Production Research Vol.43 (13), 2005, 2789-2801

[26] J. Kušar et al., How to reduce new product development time. Journal of Robotics and Computer-Integrated Manufacturing (20), 2004, 1-15

[27] K.T. Ulrich, S.D. Eppinger, Product design and development (Third Edition). New York: McGrawHill/Irwin , 2004

[28] S. Hart, E.J. Hultink et al., Industrial companies' evaluation criteria in new product development gates, Journal of Product Innovation Management (20), 2003, 22-36

[29] G. Boyle, Design project management, England: Ashgate Publishing Limited, 2003

[30] M. Baxter, Product design practical methods for the systematic development of new products. USA Chapman \& Hall, 2002

[31] C. Bendedetto, Identifying the key success factors in new product launch, Journal of Product Innovation Management (16), 1999, 530-544

[32] B. Prasad, Wang, F., J. Degn, A concurrent workflow management process for integrated product development, Journal of Engineering Design. (9-2), 1998, 121-135

[33] R.G. Cooper, Perspective third-generation new product process, Journal of Product Innovation Management (11), 1994, 3-14

[34] R.G. Cooper, S.J. Edgett et al., Now product portfolio management: practices and performance, Journal of Product Innovation Management (16), 1999, 333-351 